\title{
Synthesis and Characterization of Polysiloxane and Acrylate Elastomer Material
}

\author{
Lei XU ${ }^{a}$, Min WANG ${ }^{b}$, Xi-Zhi JIANG ${ }^{c}$, Yong-Fu ZHAO ${ }^{\text {, }}{ }^{*}$ \\ ${ }^{1}$ Institute of Agricultural Facility and Equipment, Jiangsu Academy of Agricultural Sciences, China

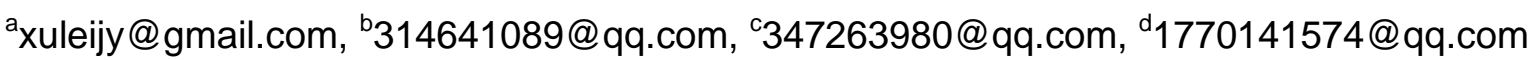 \\ *corresponding author
}

Keywords: Polysiloxane Monomer, Emulsion Polymerization, Block Copolymerization.

\begin{abstract}
High silicon content silicone-acrylate block copolymerization emulsion by vinyltriethoxysilane acrylate(VTS), octamethylcyclotetrasiloxane(D4) and acrylic ester was synthesized in this paper. About $20 \mathrm{wt} \%$ silicon gave the latex film characteristic of rubber by the study on the resilience and tensile curve of the silicone-acrylic latex film. The emulsion conforms to the characteristics of dilute polymer solution and the law of Newtonian Fluid. Morphology structure of the latex film was determined by transmission electron microscopy(TEM). The analysis results indicated that the latex film presented a high drawing rate and a high elasticity. Compared with common polymer fluid, the latex displayed a sound performance in flow ability, elastic resilience and industry application value.
\end{abstract}

\section{Introduction}

Silicone elastomers are well known for their interesting physical and chemical properties such as low surface tension and surface energy, high energy of Si-O bond and good molecule flexibility[1]. Recently, improvements of heat resistance and water resistance of acrylate have been the main direction of the modification of acrylate[2-4]. Among all these researches, the emulsion copolymerization of acrylate monomer and unsaturated organosilicon coupler is of vital importance. However, the content of organsilicon in the silicone-acrylate emulsion is normally low because of the destabilized and condensed system caused by the cross-linked structure in the early stage of the polymerization which due to the hydrolysis and condensation of organosilicon monomer in the modification[5-6]. It has reported that the selection of the reactive emulsifying agents and hydrolysis depressor, and emulsificated monomer by high shear produced stable organosilicon acrylate emulsion with high content of silane. In this paper, the film formation is analyzed by TEM and the prospect of the application is introduced[7-8].

\section{Experimental}

\section{Materials}

Vinyltriacetoxysilane(VTS), octamethylcyclotetrasiloxane (D4) (Guo Tai Hua Rong, China); sodiumlauryl sulfate (SDS), polyoxyethylatedalkyphenol(OP-10)(HaiAn Shi hua, China); butylacrylate(BA), methylmethacrylate(MMA), hydroxypropylmethacrylate (HPA), 2-acrylamido-2methylpropane sulfonate (AMPS), N-methylol methacrylamide (N-MA) (Guo lian petrochem. Co., Ltd., Jiang yin, China), glycol, ammonia water, ammonium peroxydisulfate (APS) and deionized water.

\section{Synthesis of Siloxane Acrylate}

The polymerization steps were carried out under the protection of nitrogen atmosphere in a 300-ml four-neck flask equipped with reflux condenser, mechanical stirrer, thermometer and inlet for nitrogen gas.

Firstly, the mixture of D4/MMA/BA was emulsified in a mixed emulsifier (SDS/OP-10) on the magnetic stirring and the initiator(APS) solution was made. Secondly, when the temperature was 
increased to $50{ }^{\circ} \mathrm{C}, 20 \%$ of the emulsified solution and $20 \%$ of the APS solution was added into the reactor. The rest emulsified solution was dispersed and emulsified by the high sheer machine. Thirdly, the rest $80 \%$ solution and another part of APS were added drop-by-drop during 2 hours while the solution in the reactor turned into light blue. After the addition of all these materials, the temperature was maintained and last for 2 hours. When the reaction was over, the temperature was reduced to $25^{\circ} \mathrm{C}$ and the reaction was terminated by the addition of ammonia water(PH 7-8).

\section{Characterization of the Latexes and Films}

The gel content was measured by gravimetric analysis. Filtrated a certain quantity of emulsion $\left(\mathrm{m}_{1}\right)$ with a colatorium after the reaction dried to a constant weigh $\left(\mathrm{m}_{2}\right)$ in a dry oven at $120^{\circ} \mathrm{C}$. The gel content was calculated by the following formulas:

gel content $(\%)=\frac{m_{2}}{m_{1}} \times 100$

The viscosity of the emulsion was measured by NDJ-8 rotational viscosimeter under room temperature.

The stretching behavior of the film was tested on the 3365 multipurpose tensilometer (Instron co.Ltd), sampling with dumbbell cutting shear. The tensile speed was $200 \mathrm{~mm} / \mathrm{min}$.

A TecnaiG-220 TEM (FEI co. US) was used to observe the configuration particles and the morphology structure. The emulsion sample was diluted to around $1 \mathrm{wt} \%$ by deionized water. The particle morphology of latex was obtained after the dropwise of the emulsion on the copper mesh with carbon film.

The Shear stress and shear speed were tested on waters1515 (Virian Inc, US).

\section{Results and Discussion}

\section{Synthesis of Organosilicon Acrylate}

In this research, one of the methods to increase the content of organosilicon was the add amount of D4. The active center firstly attcked the tensile cyclic siloxane when the ring-expansion polymerization happened and made it the lineal siloxane. The active center then attacted the unsaturated double-bonds equiprobably and made a polymer obtained by the reaction of butyl acrylate, methyl methacrylate and vinyl triacetoxysilane. In most studies about BA, MMA and VTS, as shown in Fig.1, whether alcohol-bonds in lineal siloxane react with the double-bonds in VTS to A polymer or the other bond of R3 in VTS to B polymer remain unsolved. Therefore, the resultant polymer $\mathrm{A}$ is easier to form than $\mathrm{B}$, so the routine of polymerization to $\mathrm{A}$ is more possible.<smiles>[R20]OC(=O)C(=C)C(=C)[CH+]C=C(C)[Si]([R3])([R3])[R17]</smiles>

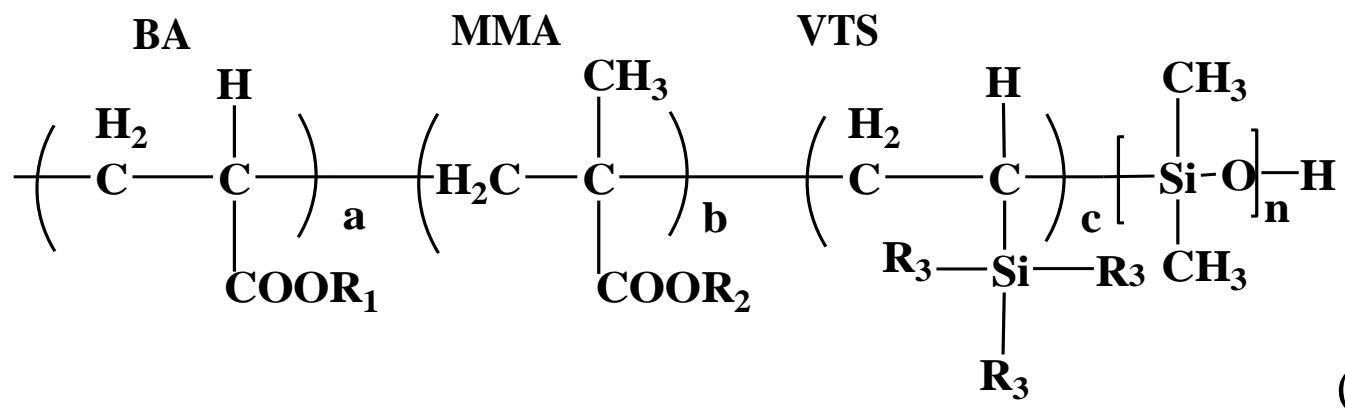




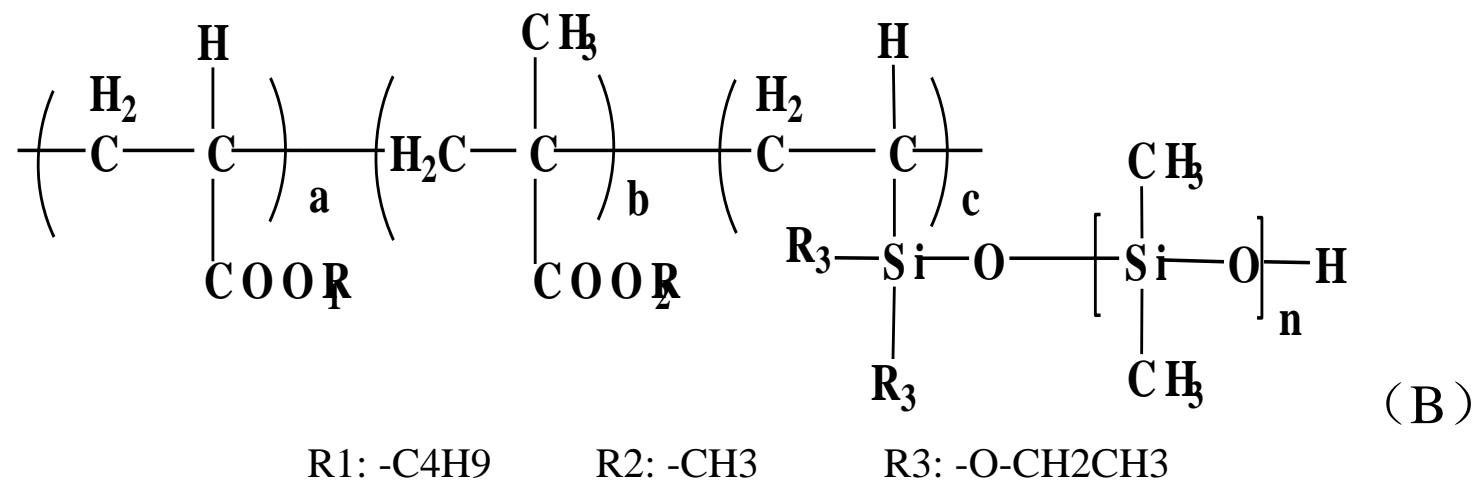

Fig.1 Reaction routine for alkoxysilane modified acrylic latex

\section{The Effect of Organosilicon Content on Viscosity and the Elongation at Break of the Film}

According to Tab.1, viscosity of the emulsion rises definitely with the addition of silicon monomer content when the component remains unchanged. The addition of viscosity will break the fluidity of the emulsion, although it will improve the behavior of the emulsion. The elongation at break of the film increased when the silicon content was increased, it decreased when the content of silicon monomer was higher than $8 \%$ and increased gradually when the content was higher than $20 \%$. This is because the silicon monomer is easy to hydrolyze, cross-linked and polycondensationin reacted in water. The tensile strength increased because of the cross-linked netlike structure caused by the continuously addition of silicone. The elongation at break increased gradually when the degree of cross-linking was not large in the beginning when the organosilicone content was below $8 \%$, however, it decreased when the silicon content was more than $8 \%$, because the formation of new fazes in this stage interfered to elongation. But the elongation at break of the latex film increased when the content of silicon was more than $16 \%$ because of the good compliance of chains of the polysiloxane. Therefore, the content of silicone should not be too low in the research in order to synthesize a heavy intensity and a large elongation at break material.

Tab.1 Effect of content of silicon on the properties of latex film

\begin{tabular}{|c|c|c|c|}
\hline $\begin{array}{c}\text { Organosilicone } \\
\text { content } \%\end{array}$ & $\begin{array}{c}\text { Viscosity } \\
(\mathrm{mPa} \cdot \mathrm{s})\end{array}$ & $\begin{array}{c}\text { Tensile strength } \\
(\mathrm{MPa})\end{array}$ & $\begin{array}{c}\text { Elongation at } \\
\text { break } \%\end{array}$ \\
\hline 2 & 0.012 & 0.18 & 842.71 \\
\hline 8 & 0.018 & 0.29 & 1207.29 \\
\hline 12 & 0.024 & 0.61 & 1131.04 \\
\hline 16 & 0.028 & 0.63 & 851.46 \\
\hline 20 & 0.037 & 0.66 & 1058.54 \\
\hline 24 & 0.040 & 0.93 & 1082.08 \\
\hline
\end{tabular}

\section{The Influence of the Content of Silicon on Resilience Rate}

During the practical appliance, the latex film is required of the property of immediate reinstatement within limits for the effect of protection. The influence of the content of silicon on resilience rate were shown in Fig.2. The resilience effects tended to be good because of an increased amount of silicon, it increased quickly when the content of silicone was less than $12 \%$ while the content was more than $12 \%$ it increased slowly. The reason was the formation of a cross-linked netlike structure by the polymerization of the hydrolysis silicon monomer and acrylate and the original curled large molecules began to stretch under an external force. When the external force was removed, the polymer of netlike structure were easier to rebound than those ones of lineal chain. Therefore, the content of silicone monomer should be more than $12 \%$. In this study, $20 \%$ content of silicone monomer was chosen. 


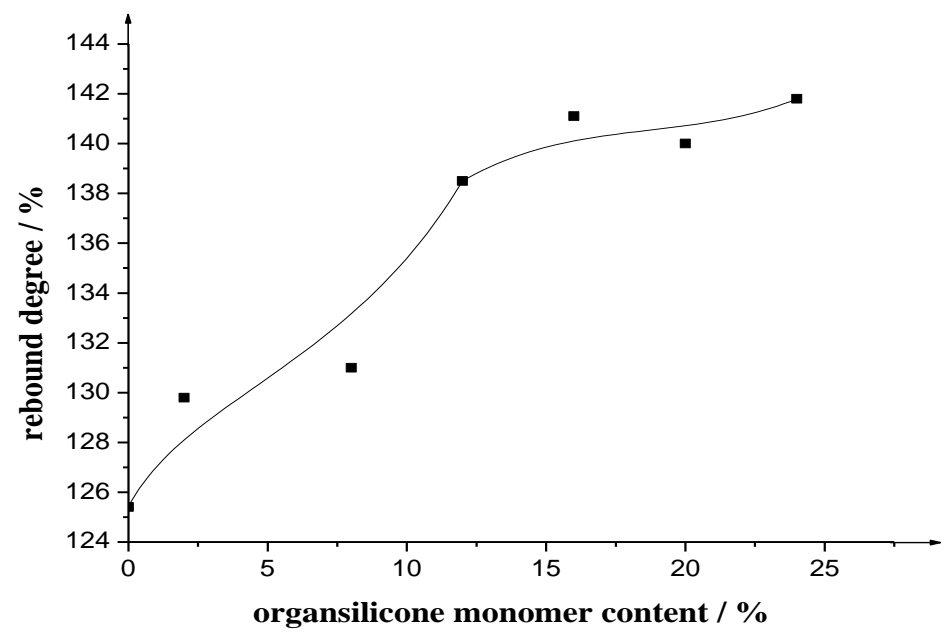

Fig.2 Influence of organsilicone monomer content on film resilience rate

\section{Analysis of the Stress Curve of the Latex}

The comprehensive properties of the latex increased effectively by the increasing silicon content. When the silicone monomer content reached to $20 \%$, the stress curve of the elasticity film was a typical rubber stress curve. Fig. 3 shows the characteristics of the rubber stress curve. The curve exhibited a low Young modulus, that was a large deformation under a small external force. The latex film was stretched from the original length of $40 \mathrm{~mm}$ and it did not crack down until the length of $440 \mathrm{~mm}$. The fact that a large elastic deformation under a small external force gave the evidence that the molecular chain of the products have a good compliance structure. The polysiloxane has a high-temperature stability because $\mathrm{Si}-\mathrm{O}$ bond has a higher energy than $\mathrm{C}-\mathrm{C}$ bond and $\mathrm{Si}-\mathrm{O}-\mathrm{Si}$ has a big bond angle, long $\mathrm{Si}-\mathrm{O}$ bonds, a free rotation of $\mathrm{Si}-\mathrm{O}-\mathrm{Si}$ in the main chain and a chain with a good compliance. The acting force between the molecule is small and the molecule is nonpolar. The polysiloxane has very low glass-transition temperature, often at $-123^{\circ} \mathrm{C}$, and a good compliance at a low temperature. The Si-O-Si main chain is helical and rotate easily. The nonpolar alkyl or aryl groups in the chain could orientate quickly to the interface. The local Si-O bond should be a polar bond because the electronegativity between the atoms, but the polarity neutralizes because of the symmetry and the nonpolar side chains. Therefore, the molecular appears to be nonpolar, and the polysiloxane has a low interfacial tension.

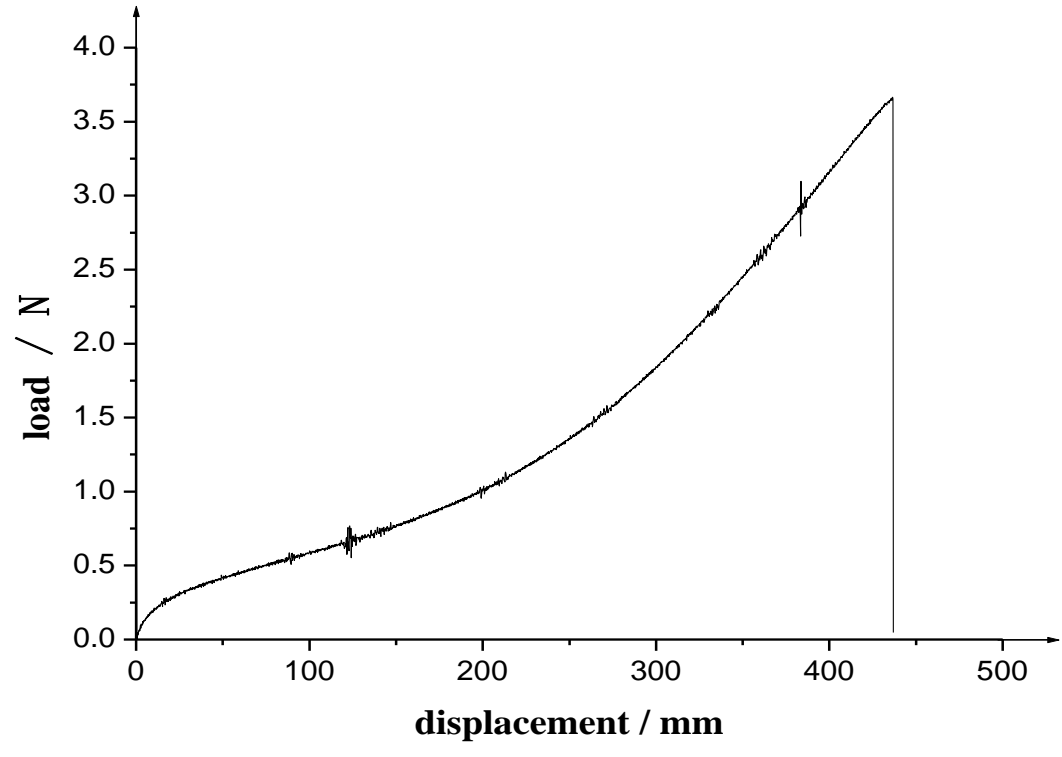

Fig.3 Stress curve of the latex 


\section{Analysis of Film Formation Process of the Latexes}

Fig.4-Fig.6 show the TEM photos of different filming time of the silicon acylate latexes. Fig.4 shows the shape of a single particle of the silicon-acrylate latexes which is about 50-120nm in diameter, when many particles of the latexes had a same orientation and a regular arrangement, rod-liked micro units could be formed. Fig.5 shows the Rod-like micro units formed by the emulsion particle of the latexes with a length of $0.4-0.6 \mathrm{um}$ and a diameter of $50-120 \mathrm{~nm}$. The cross-linked structure of the rod-like micro units is shown in Fig.6. The latexes have a good stability because of the interpenetrating network structure of the polymer. From the structure shown in the picture, each rod-like microunit could be stretched while endured an external force, so the film could present an excellent tensile strength.

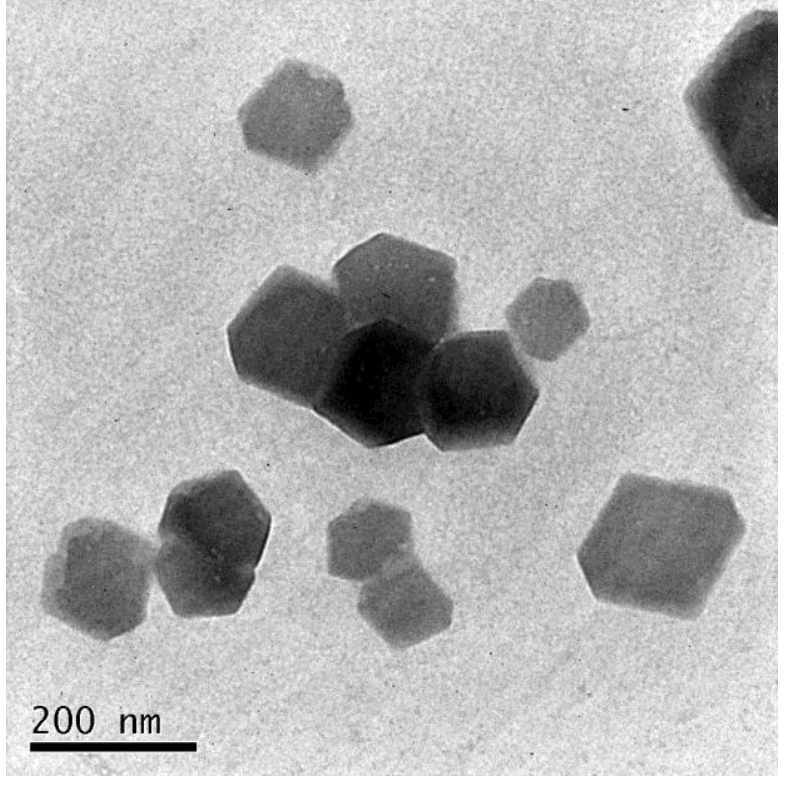

Fig.4 TEM photograph of the latex particles

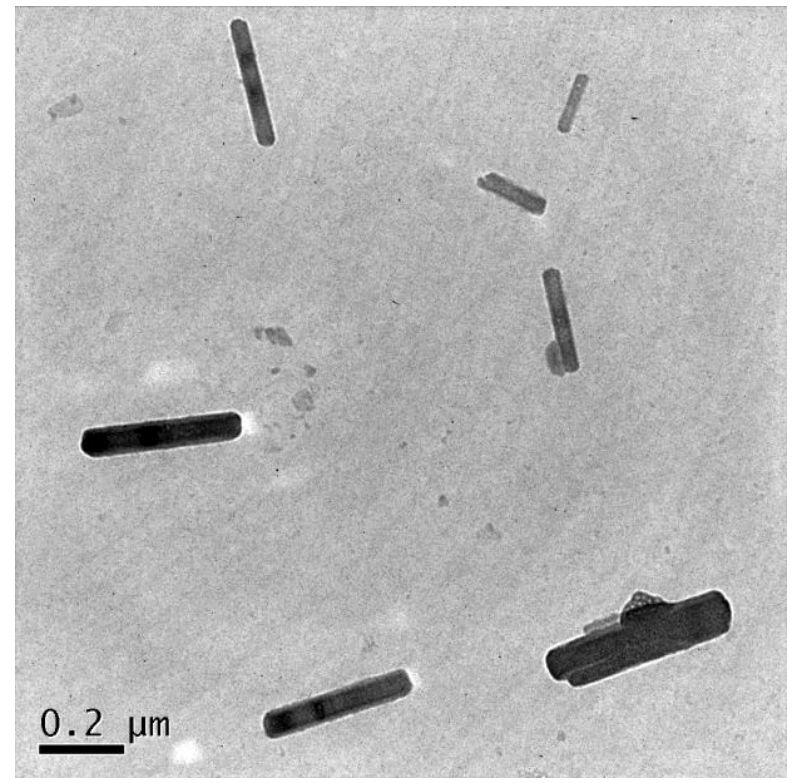

Fig.5 TEM photograph of the latex stickes

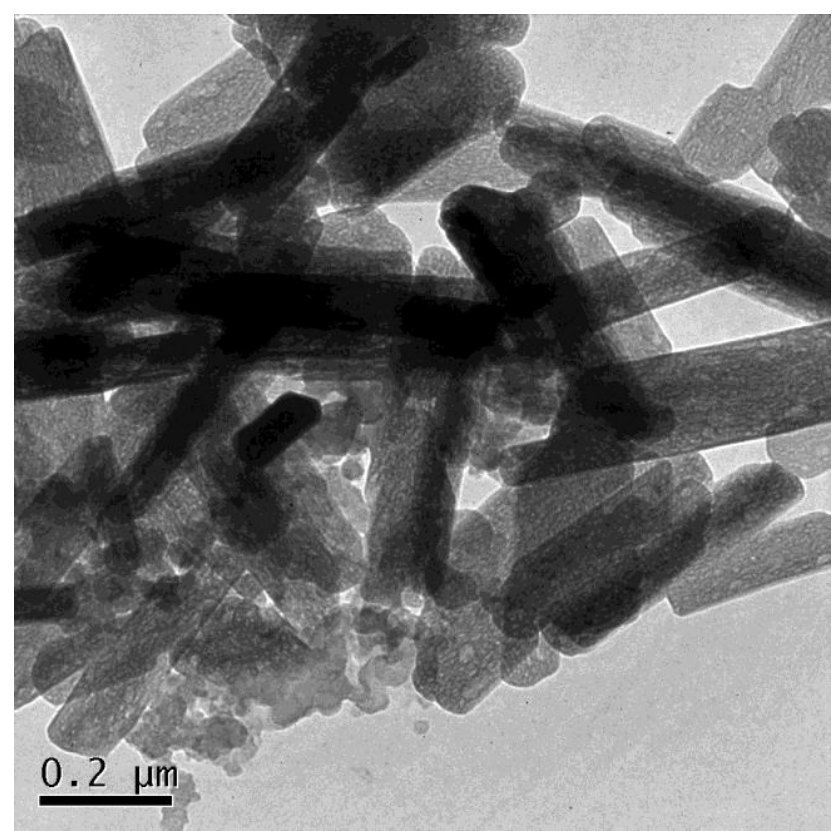

Fig.6 TEM photograph of the latex

\section{Rheological Behavior of the Silicon-acylate Latexes}

When the small molecule fluid flowed, the higher speed, the more resistance it endured. Newton fluid equation demands that shearing stress is proportional with shearing rate. The constant between 
them is called viscosity, which represents the viscosity resistance it endures in unit area per second. The fluid whose viscosity remains a constant when the shearing stress and shearing rate change is called Newton fluid which includes small molecule solution and large molecule dilute solution. The rheological behavior of the latexes in this research is shown in Fig.7. In the beginning stage, the fluid turned to be dense, and then it accorded to the law of Newton fluid. It proved that the emulsion polymerization was a dispersion system and the solution which complied with the Newton fluid law was still dilute while the content of silicon was $30 \%$. In the other process of painting or extrusion, the film probably expanded or deformed because the common polymer fluids do not accord with the Newton fluid law. Therefore, it would be a great advantage to film by the spraying of the silicon-acrylate latexes. The rheological behavior of the emulsion was close to water, so it will have a broad industrial appliance.

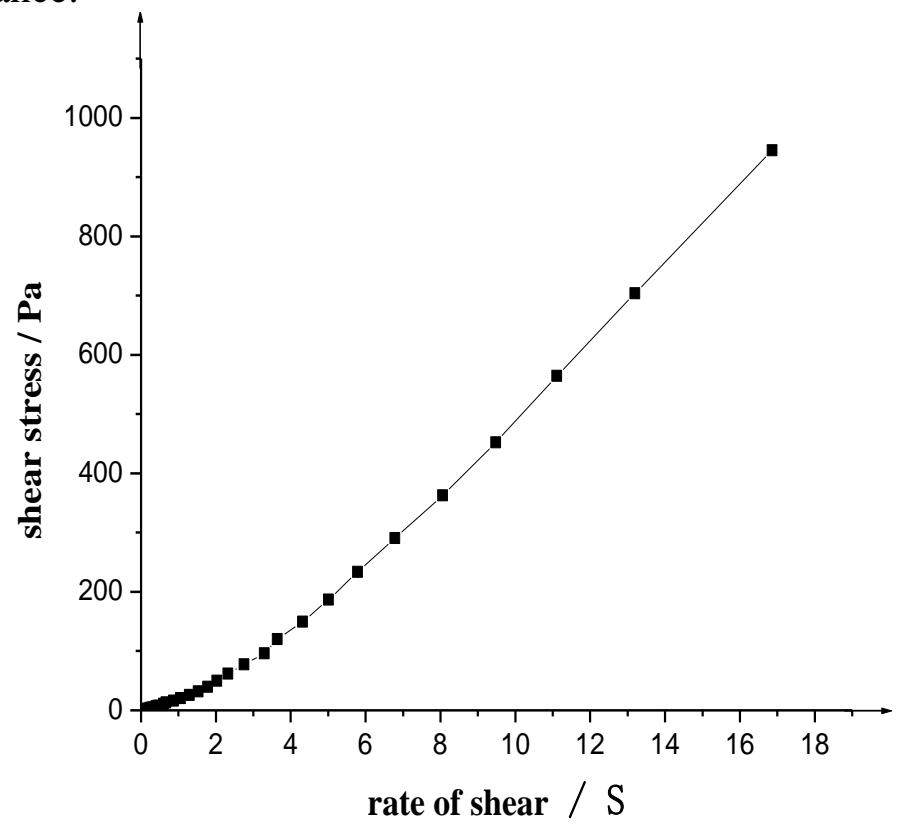

Fig.7 Rheological behavior of the latex

\section{Conclusion}

The synthesis of emulsion polymer and the reshaping of acrylate emusion by organosilicon were discussed in this paper. $\mathrm{D}_{4}$ was used to increase the content of organosilicon and a possible routine of the polymerization was designed. A heavy intensity and a large elongation at break material was synthesized with a proper content of silicone. The rheological behavior of the emulsion was proved to be close to water and the film formation process was convenient. Rebound behavior and the stress curve of the film were tested and characterized. A good explanation of the structure of high stretching rate and rebound behavior of the film was given through the analysis of the micromechanism of the film formation process. It remained a dilute solution of polymer when the content was $30 \%$ through the rheological analysis of the silicon and acrylate latexes, so it will have a bright prospect in the industrial appliance.

\section{Acknowledgement}

This research was financially supported by Nonprofit industry research subject (201103007) .

\section{References}

[1]Moretto HH, Schulze M, Wagner G.Silicones. In: Elvers B,Hawkins S, Russey W, Schulz G, editors.Ullman encyclopedia of industrial chemistry, 5th ed, vol.24. Deerfield Beach, FL, USA:VCH Publishers; 1993.p.57. 
[2]HUANG S Q , PENG H, L I S B. Studies on PHMS/ BA composite emulsion :the effect of PHMS on the properties of emulsion and the polymerization mechanism[J ] . Polymer Materials Science \& Engineering, 2000,16 (5) : 22225.

[3]LUO Y W, XU H J , LI B F. Synthesis and properties of alkoxysi-lane-modified acrylic latex via miniemulsion polymerization [J ] . Journal of Chemical Industry and Engineering , 2006 , 57 ( 12) : 2981-22986.

[4]XU Y, XING P, XIE H D, XU G H. Performances and Preparation of Polysiloxane and Acrylate Elastomer.[J]. Polymer Materials Science \& Engineering, 2009, 25(2).

[5]De Gunzbourg A,Favier J C ,Hemery P. Polym Int ,1994 ,35 (2) :179-188.

[6]XIA Y.J., YU Z.Q., NI P.H., Minimulsion copolymerzation of methylmethacrylate and r-(methacryloxy) Propyltrimethoxy silane[J], Polym. Mater. Sci. Engin., 2005, 21: 102-105.

[7]Luo Y.W., Xu H.J., Li B.F., Synthesis and properties of alkoxysilane-modified acrylic latexvia miniemulsion polymerzation[J]. J. Chem, Ind, Engin., 2006, 57(12): 2981-2986.

[8]WU Y.M., YU H.D., ZHANG C.G., Preparation and performance in paper coating of silicone-modifiedstyrene-butylacrylate copolymer latex[J], Appl. Polym. Sci., 2001, 79(2): 333-336. 